\title{
On-board observation of SPEs and its contribution in the radiation exposure on electronics at different orbits in 24th cycle
}

\author{
Grigory A. Protopopov* \\ Branch of JSC URSC-ISDE $n$ \\ E-mail: g.a.protopopov@mail.rul \\ Vasily S. Anashin \\ Branch of JSC URSC-ISDE \\ Igor A. Lyakhov \\ Branch of JSC URSC-ISDE

\section{Sergey O. Rukavichnikov} \\ Branch of JSC URSC-ISDE \\ Valentina I. Denisova \\ FSBI Fedorov Institute of Applied Geophysics
}

\section{Alexey V. Tsurgaev}

FSBI Fedorov Institute of Applied Geophysics

\begin{abstract}
In the paper results of on-board data from different spacecrafts and different orbits during different solar proton events in 24th solar cycle for several years are presented. Data from spectrometers placed onboard Russian spacecrafts Electro-L and Meteor-M, functioning at geostationary and polar orbits correspondingly are used, and also free access data from GOES and POES are used. Solar proton fluxes were determined for different events for several years in 24th solar cycle at geostationary orbit according to measurements of Electro-L and GOES spacecrafts as well as at polar orbit according to measurements of Meteor-M. Single events upset rate values were calculated for different events in different orbits using measured and model solar proton spectra. Analysis results of comparing of solar proton events frequency and magnitude for different years of 24th solar cycle were discussed. We show that solar proton events contribution vary considerably depending on the event and the orbit type.
\end{abstract}

35th International Cosmic Ray Conference - ICRC2017

10-20 July, 2017

Bexco, Busan, Korea

${ }^{*}$ Speaker. 


\section{Introduction}

The space radiation is one of the most important factors which can lead to failure of electronic devices and spacecrafts. According to Goddard Space Flight Center Space Mission Operations Team [1], 59\% of Earth and space science missions were impacted by "space weather", including solar and galactic cosmic rays. Half of spacecraft anomalies were caused by space radiation factors [2], [3], and most of them occurred due to electrostatic and single event effects. The latter are driven basically by solar and galactic cosmic rays. So, it is important to monitor solar and galactic charge particle's flux in order to estimate the level of space radiation exposure on electronic components and devices. For this purpose the monitoring system of space radiation exposure on spacecraft equipment was made on demand of Roscosmos [4]. The monitoring system processes various flight data including spectrometer's data from METEOR-M spacecraft, which operates in polar orbit 832 $\mathrm{km}$ altitude, and ELECTRO-L spacecraft which operates in geostationary orbit [4]. The in-flight data have been accumulating for more than 5 years (since 2010). In this paper we present processed flight data from Meteor-M and Electro-L and the estimation of 24th solar cycle's solar proton events (SPE) contribution in the space radiation exposure on electronics at polar and geostationary orbits.

\section{On-board measurements used}

ELECTRO-L on-board measurements include fluxes of protons with different energy ranges: from $13.7 \mathrm{MeV}$ to $23 \mathrm{MeV}$; from $23 \mathrm{MeV}$ to $42 \mathrm{MeV}$; from $42 \mathrm{MeV}$ to $112 \mathrm{MeV}$. METEOR-M on-board measurements include total fluxes of protons and electrons with energies: more than 0.7 $\mathrm{MeV}$ for electrons and more than $15 \mathrm{MeV}$ for protons, more than $1.5 \mathrm{MeV}$ for electrons and more than $25 \mathrm{MeV}$ for protons, and more than $6 \mathrm{MeV}$ for electrons and more than $600 \mathrm{MeV}$ for protons. Also we use free access data from GOES [5]: daily integral proton flux with energy more than 10 $\mathrm{MeV}$ and $100 \mathrm{MeV}$.

\section{Determination of SPE spectra}

To determine SPE spectra at geostationary orbit we use integral daily proton fluxes which are measured by Electro-L and GOES during events (an event can run on several days). The event start when proton flux with energy more than $10 \mathrm{MeV}$ exceeded the level of 10 proton/cm2/s/sr, the list of SPE can be found for example here [6]. We take into account a background of proton's flux (the annual level of proton flux in absence of SPE). The power dependence is used to approximate the experimental data (it is possible for the energy range under consideration, this range is the most interest because typical electronics component's sensitivity to proton exposure lies between 15-50 $\mathrm{MeV})$.

Fig. 1 show an example of derived SPE spectrum from Electro-L and GOES data at geostationary orbit for 16.03.2013 event, blue diamonds represent Electro-L data, green triangles represent GOES data. One can see that there is a good agreement of GOES and Electro-L data, which is observed for all events.

To determine SPE spectra at polar orbit we use integral daily particle's fluxes which are measured by Meteor-M during events. We determine SPE flux during an event as a particle's flux in 
polar regions (L-shell in more than 4), details of the approach is described in [7]. To take into account contaminations of electrons in particle's flux we remove background flux, which was calculated as an average particle's flux in polar region during 5 days before given event. Fig. 2 show an example of derived SPE spectrum from Meteor-M data at polar orbit for the same event.

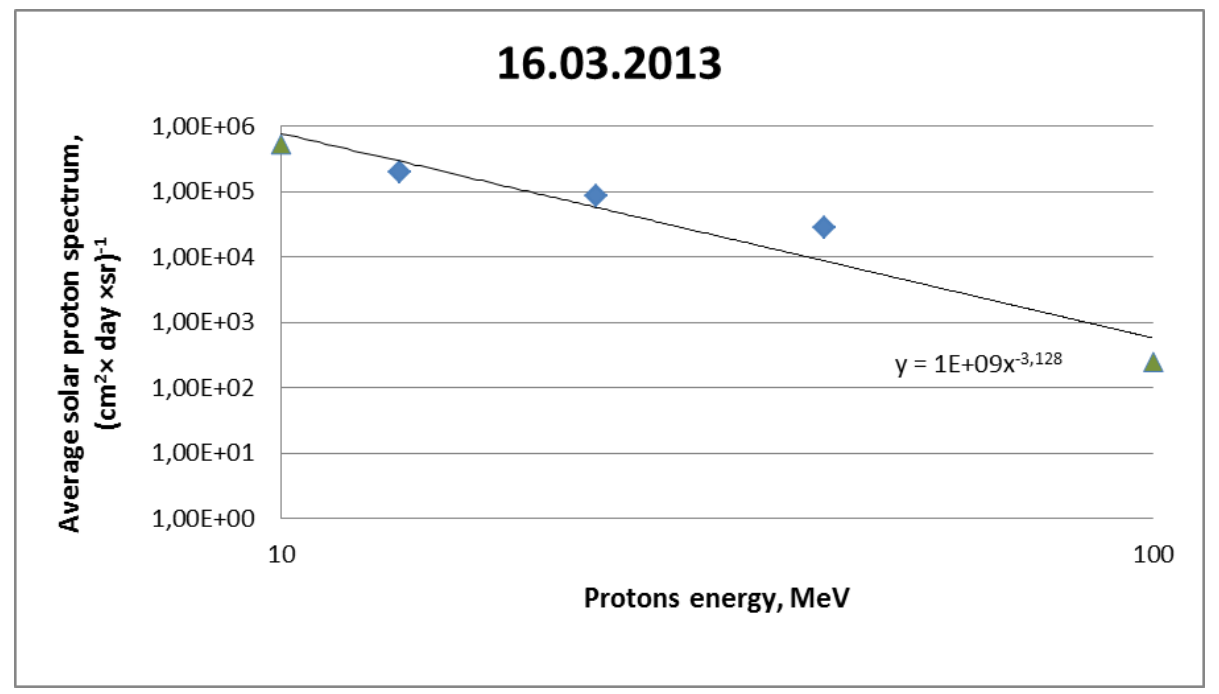

Figure 1: SPE spectrum at geostationary orbit for 16.03.2013 event (blue diamonds - Electro-L data, green triangles - GOES data) and power approximation of data

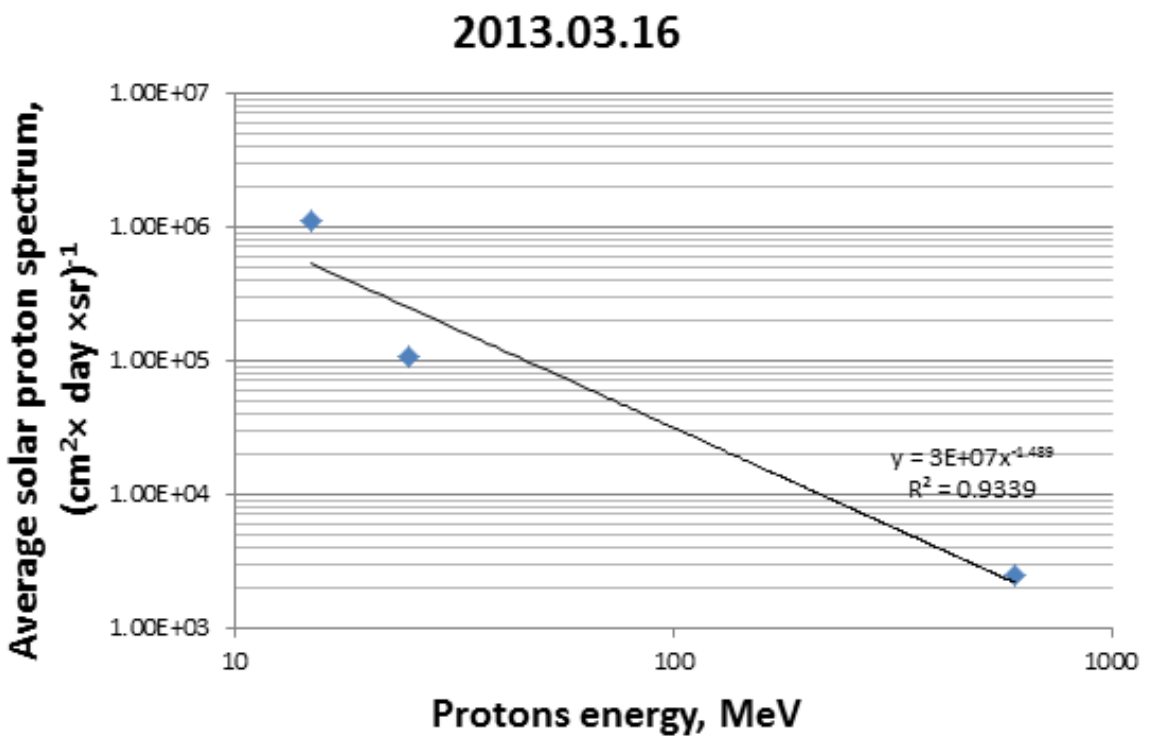

Figure 2: SPE spectrum at polar for 16.03.2013 event from Meteor-M data and power approximation of data

One can see that spectrum's magnitude at polar orbit is less than one at geostationary orbit, it is occurred because of geomagnetic cutoff rigidity. 


\section{Derived SPE spectra}

Fig. 3 show SPE spectra at geostationary orbit for all events in 2013. Analogous spectra were derived for 2011-2015.

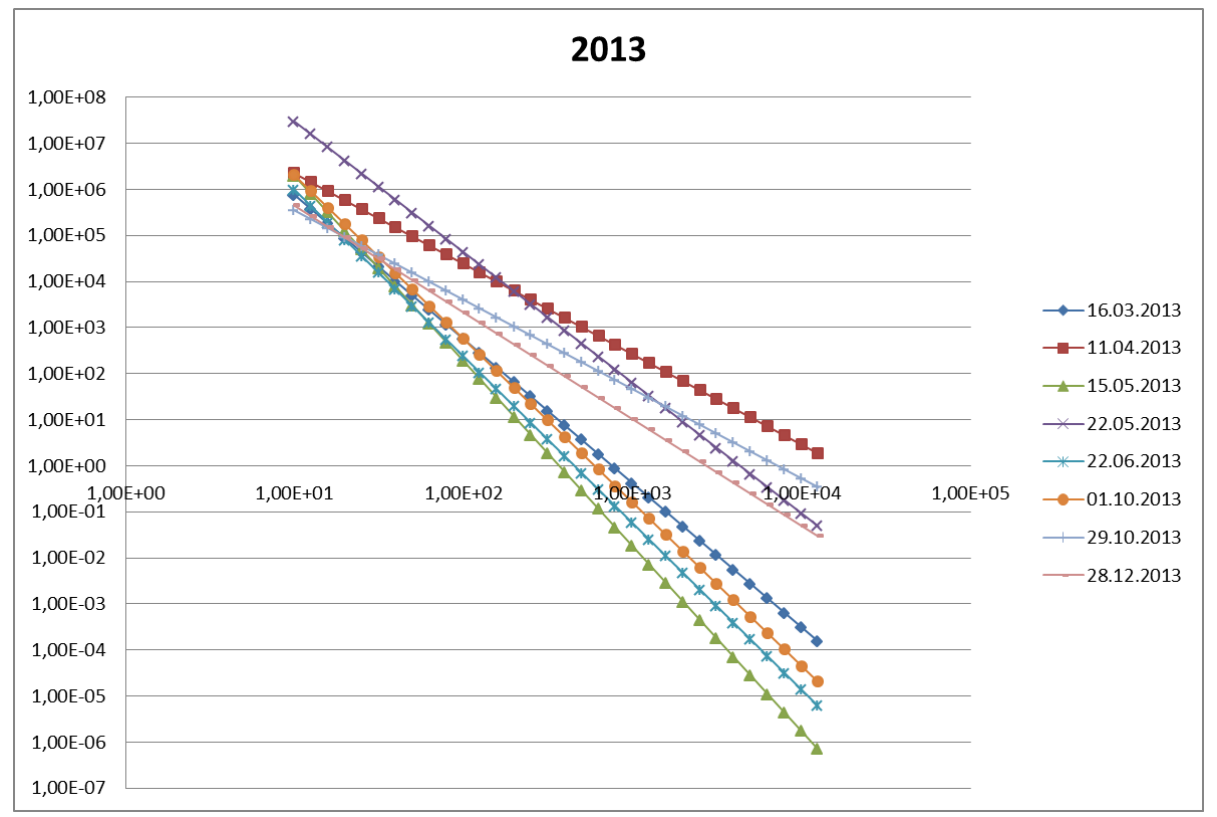

Figure 3: SPE spectra at geostationary orbit for all events in 2013

Analogous selection of SPE spectra at polar orbit are presented in Fig. 4.

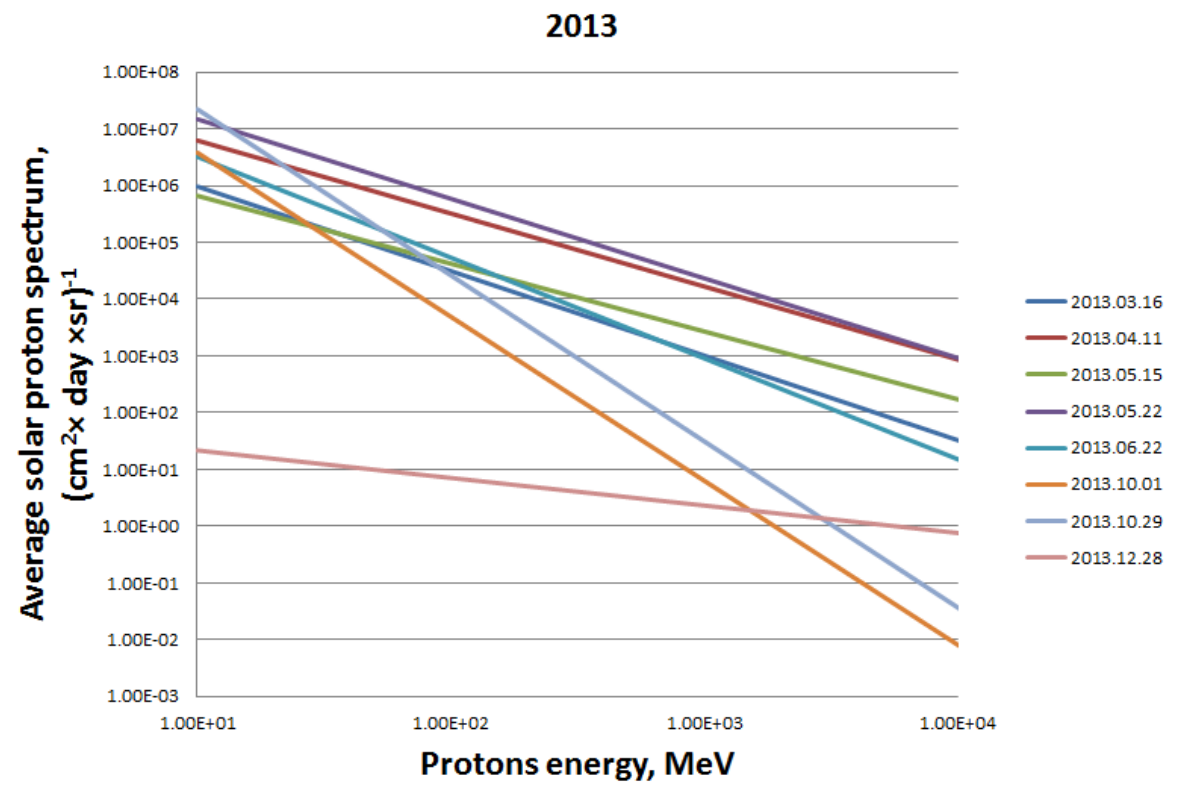

Figure 4: SPE spectra at polar orbit for all events in 2013 
One can see that SPE spectra have different magnitude and slope (dispersion in 2013 is equal $27 \%$ for geostationary orbit), so SPEs can differ markedly from each other as in rigidity aspect as in magnitude aspect even during one year.

Fig. 5 and 6 show maximal SPE spectra at geostationary and polar orbit for different years. The maximal spectrum is observed in 2012.

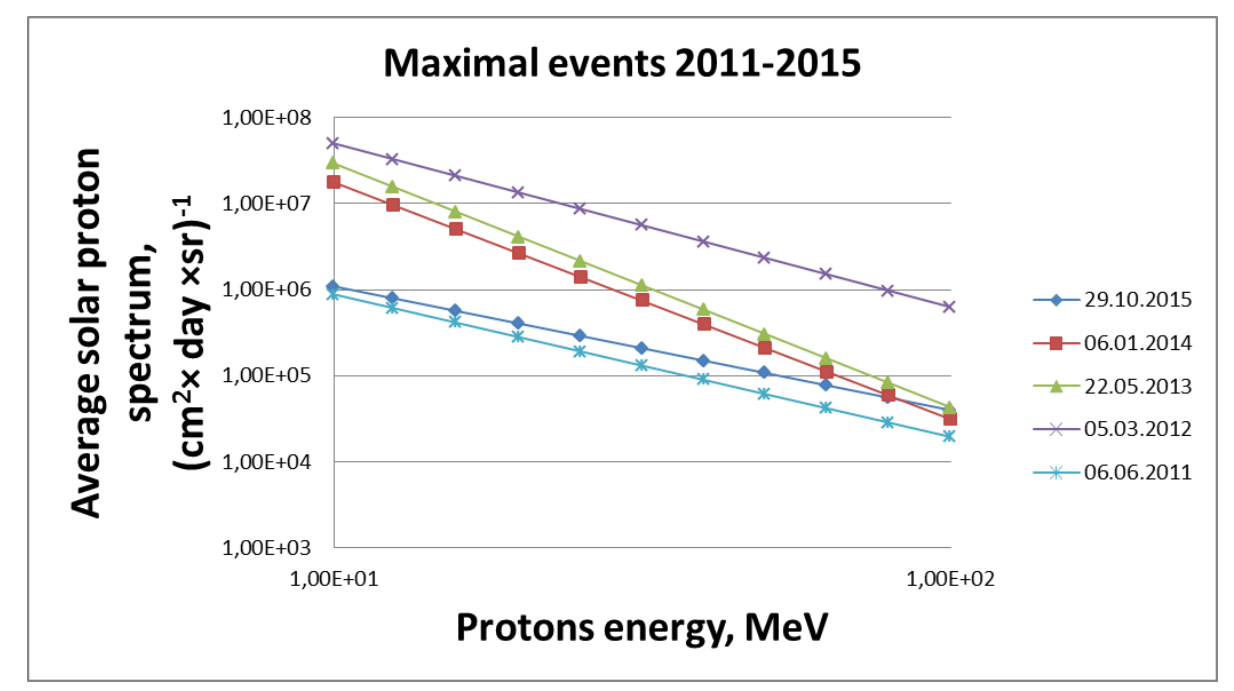

Figure 5: Maximal SPE spectra at geostationary orbit

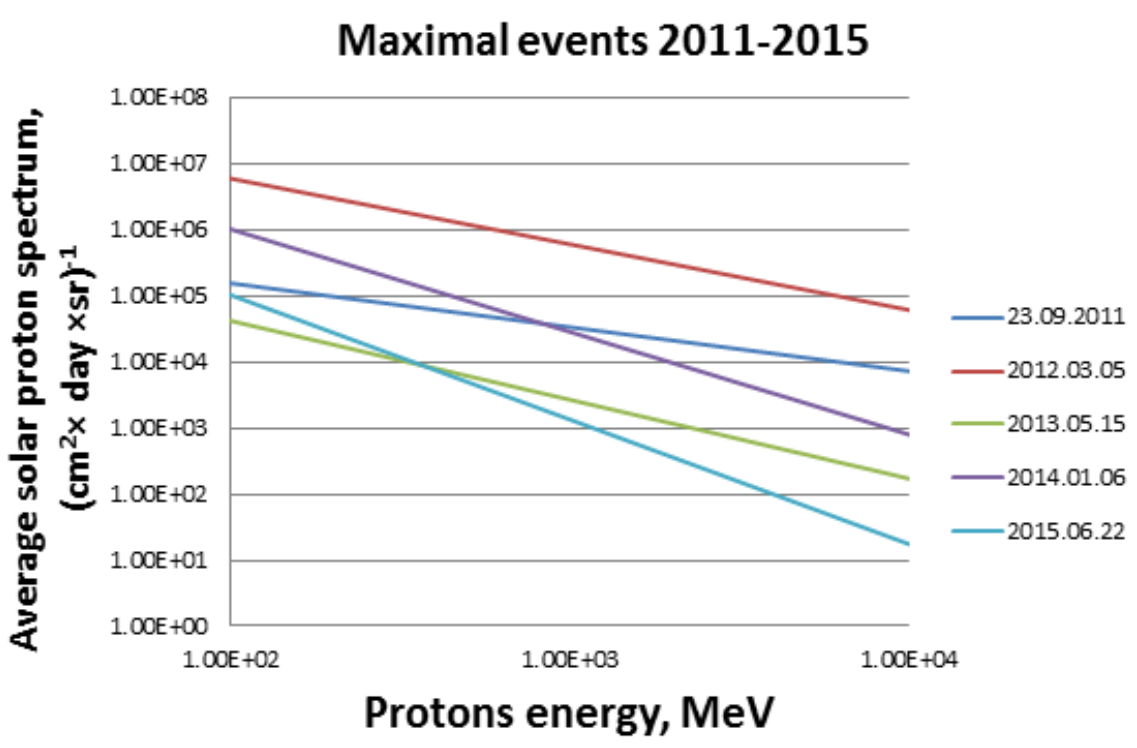

Figure 6: Maximal SPE spectra at polar orbit

Table 1 show summary data about maximal characteristics of SPE spectra at geostationary orbit: the most rigid spectrum slope (multiplied by 10), the most spectrum magnitude (logarithm of the magnitude), total number of event, and also yearly mean total sunspot number (divided on 10) [8]. It is interesting that years with maximal characteristics do not match with year with 
maximal sunspot number (2014): 2012 has maximal number of events and spectrum magnitude, 2013 - maximal spectrum rigidity. So, SPE spectra characteristics depend on not only solar activity (sunspot number).

\begin{tabular}{l|l|l|l|l} 
Years & Slope*10 & Log(magnitude) & Number of events & SSN/10 \\
\hline 2011 & 16.6 & 9.7 & 7.0 & 8.1 \\
2012 & 19.0 & 10.8 & 13.0 & 8.5 \\
2013 & 19.4 & 10.3 & 7.0 & 9.4 \\
2014 & 15.7 & 10.0 & 6.0 & 11.3 \\
2015 & 14.4 & 9.7 & 4.0 & 7.0
\end{tabular}

Table 1: The most rigid spectrum slope (multiplied by 10), the most spectrum magnitude (logarithm of the magnitude), total number of event, and also yearly mean total sunspot number (divided on 10) for different years

\section{Single event effects rate calculation}

To calculate single event rate (SER) we use sensitivity parameters of electronic component, which were determined during radiation test [9], [10]. Calculation results for geostationary and polar orbits are presented in Table 2 and 3.

\begin{tabular}{l|l|l|l|l|l|l|l|l|l}
2015 & SER & 2014 & SER & 2013 & SER & 2012 & SER & 2011 & SER \\
\hline 15.03 & $1.6 \mathrm{E}-01$ & 06.01 & $1.5 \mathrm{E}+01$ & 16.03 & $1.3 \mathrm{E}-01$ & 23.01 & $5.8 \mathrm{E}+01$ & 21.03 & $2.0 \mathrm{E}-01$ \\
12.05 & $4.9 \mathrm{E}-02$ & 19.02 & $4.9 \mathrm{E}-02$ & 11.01 & $1.3 \mathrm{E}+00$ & 25.02 & $8.2 \mathrm{E}-02$ & 06.06 & $1.4 \mathrm{E}+00$ \\
18.06 & $3.5 \mathrm{E}-01$ & 24.02 & $1.8 \mathrm{E}+00$ & 15.05 & $6.9 \mathrm{E}-01$ & 05.03 & $6.3 \mathrm{E}+01$ & 04.08 & $1.3 \mathrm{E}+00$ \\
22.06 & $5.8 \mathrm{E}-01$ & 18.04 & $5.7 \mathrm{E}-01$ & 22.05 & $1.2 \mathrm{E}+01$ & 17.05 & $1.6 \mathrm{E}+00$ & 09.08 & $2.5 \mathrm{E}-01$ \\
02.07 & $3.4 \mathrm{E}-02$ & 03.09 & $7.9 \mathrm{E}-01$ & 22.06 & $2.1 \mathrm{E}-01$ & 07.07 & $5.4 \mathrm{E}-01$ & 23.09 & $7.1 \mathrm{E}-01$ \\
29.10 & $4.3 \mathrm{E}-01$ & 02.11 & $1.1 \mathrm{E}-01$ & 01.10 & $4.4 \mathrm{E}-01$ & 12.07 & $5.1 \mathrm{E}-01$ & 26.11 & $5.2 \mathrm{E}-01$ \\
& & & & 29.10 & $1.6 \mathrm{E}-01$ & 17.07 & $2.4 \mathrm{E}+00$ & & \\
& & & & 28.12 & $1.7 \mathrm{E}-01$ & 01.09 & $4.5 \mathrm{E}-01$ & & \\
& & & & & & 28.09 & $1.9 \mathrm{E}-01$ & & \\
& & & & & & 27.05 & $6.7 \mathrm{E}-02$ & & \\
\hline total & $1.6 \mathrm{E}+00$ & & $1.8 \mathrm{E}+01$ & & $1.5 \mathrm{E}+01$ & & $1.3 \mathrm{E}+02$ & & $4.4 \mathrm{E}+00$
\end{tabular}

Table 2: Single events rates during SPE at geostationary orbit for different years

One can see that there is a strong variation of single events rates during one year and during 5 years too. For example, difference between maximal and minimal rates at geostationary orbit for 2011 is 7 times, for 2012 - 770 times, for 2013 - 90 times, for 2014 - 310 times, for 2015 - 17 times, total rate for 2012 is greater than one for 2015 in 80 times

\section{Conclusions}

Solar proton fluxes were determined for different events for several years in 24th solar cycle at geostationary orbit according to measurements of Electro-L and GOES spacecrafts as well as 


\begin{tabular}{l|l|l|l|l|l|l|l|l|l}
2015 & SER & 2014 & SER & 2013 & SER & 2012 & $S E R$ & 2011 & SER \\
\hline 15.03 & $2.7 \mathrm{E}-01$ & 06.01 & $5.5 \mathrm{E}+01$ & 16.03 & $3.7 \mathrm{E}-01$ & 23.01 & $8.4 \mathrm{E}+00$ & 21.03 & $7.8 \mathrm{E}-01$ \\
12.05 & $5.0 \mathrm{E}-02$ & 19.02 & $1.3 \mathrm{E}-03$ & 11.01 & $5.3 \mathrm{E}+00$ & 25.02 & $2.1 \mathrm{E}+00$ & 06.06 & $7.7 \mathrm{E}+00$ \\
18.06 & $2.3 \mathrm{E}+00$ & 24.02 & $7.2 \mathrm{E}+00$ & 15.05 & $8.7 \mathrm{E}-01$ & 05.03 & $1.2 \mathrm{E}+02$ & 04.08 & $7.7 \mathrm{E}+00$ \\
22.06 & $7.6 \mathrm{E}+00$ & 18.04 & $7.2 \mathrm{E}-01$ & 22.05 & $1.2 \mathrm{E}+01$ & 17.05 & $8.3 \mathrm{E}+00$ & 09.08 & $1.9 \mathrm{E}+00$ \\
02.07 & $2.8 \mathrm{E}+00$ & 03.09 & $3.1 \mathrm{E}+01$ & 22.06 & $1.6 \mathrm{E}-01$ & 07.07 & $5.9 \mathrm{E}+00$ & 23.09 & $1.2 \mathrm{E}+00$ \\
29.10 & $1.1 \mathrm{E}+00$ & & & 01.10 & $1.2 \mathrm{E}+00$ & 12.07 & $9.3 \mathrm{E}-01$ & 26.11 & $4.1 \mathrm{E}-01$ \\
& & & & 29.10 & $6.6 \mathrm{E}+00$ & 17.07 & $4.3 \mathrm{E}+00$ & & \\
& & & & 28.12 & $2.0 \mathrm{E}-05$ & 01.09 & $7.0 \mathrm{E}+00$ & & \\
& & & & & & 28.09 & $4.1 \mathrm{E}+01$ & & \\
& & & & & & 27.05 & $1.2 \mathrm{E}+00$ & & \\
\hline total & $1.5 \mathrm{E}+01$ & & $9.4 \mathrm{E}+01$ & & $2.8 \mathrm{E}+01$ & & $1.95 \mathrm{E}+02$ & & $1.5 \mathrm{E}+01$
\end{tabular}

Table 3: Single events rates during SPE at polar orbit for different years

at polar orbit according to measurements of Meteor-M. We observed a good agreement between GOES and Electro-L data.

Single events upset rate values were calculated for different events in different orbits using derived solar proton spectra. Analysis results of comparing of solar proton events frequency and magnitude for different years of 24th solar cycle were discussed. We show that solar proton events contribution in single events rate vary considerably depending on the event and the orbit type.

\section{References}

[1] Dirk C. Gibson. Terrestrial and Extraterrestrial Space Dangers: Outer Space Perils, Rocket Risk and the Health Consequences of the Space Environment. Bentham Science Publishers Ltd - 2015. P.85.

[2] H. C. Koons, J. E. Mazur, R. S. Selesnick, J. B. Blake, J. L. Roeder, and P. C. Anderson, "The impact of the space environment on space systems," in Proc. 6th Spacecraft Charging Tech. Conf.

AFRL-VS-TR-20001578, 1, Sep. 2000.

[3] R. Ecoffet, "On-orbit anomalies: investigations and root cause determination,” in IEEE NSREC 2011 Short Course Notes, Section IV.

[4] V. S. Anashin, G. A. Protopopov, and Y. A. Milovanov, "Monitoring of space radiation in Russian federal space agency," 2011 12th European Conference on Radiation and Its Effects on Components and Systems, Sep. 2011.

[5] http://www.ngdc.noaa.gov/stp/satellite/goes/index.html

[6] https://umbra.nascom.nasa.gov/SEP/

[7] Protopopov G.A. et al. Solar particle events contribution in the space radiation exposure on electronic equipment at the polar orbit. Proceedings of Science ICRC2015 (2016) 147.

[8] www.sidc.be/silso/datafiles

[9] R. Koga, J. George, and S. Bielat, "Single Event Effects Sensitivity of DDR3 SDRAMs to Protons and Heavy Ions," 2012 IEEE Radiation Effects Data Workshop, Jul. 2012 
[10] D. M. Hiemstra and V. Kirischian, "Single Event Upset Characterization of the Spartan-6 Field Programmable Gate Array Using Proton Irradiation” 2013 IEEE Radiation Effects Data Workshop (REDW), Jul. 2013 